\title{
A FILOSOFIA DA ARTE*
}

\section{Entrevista com Arthur C. Danto}

TRADUÇÃO DO INGLÊS DE JOAQUiM TOLEDO JR.

\begin{abstract}
RESUMO
$\mathrm{Na}$ entrevista a seguir, o professor de filosofia e crítico de arte Arthur Danto discorre sobre os principais pontos de inflexão em sua carreira. Figura de proa no pensamento que envolve a arte contemporânea, Danto tece considerações sobre arte e filosofia, aponta as principais divergências entre a crítica universitária e jornalística, reflete a respeito do papel do Estado sobre a arte e defende uma estética do sentido em detrimento de uma estética da forma.
\end{abstract}

PALAVRAS-CHAVE: Arthur Danto; crítica de arte; arte contemporânea; filosofia da arte.

\section{SUMMARY}

In the following interview, professor of philosophy and art critic Arthur Danto talks about his career. Among the main scholars dealing with contemporary arts nowadays, Danto points out relations between art and philosophy, talks about the transition from academia to popular art criticism, reflects about the role of State when dealing with the arts and explains why he subscribes to an aesthetic of meanings rather than an aesthetic of forms.

KEYWORDS: Arthur Danto; art criticism; contemporary art; philosophy of art.

[*] Entrevista publicada na versão eletrônica da revista The Nation em 18 de agosto de 2005.
Aarte sempre foi motivo de inquietação para os filósofos. $\mathrm{Na}$ República, Platão a denunciou como mera imitação. Para Hegel, a arte estava subordinada à filosofia:em 1828, escreveu que a arte "em sua mais alta vocação, é e será para sempre uma coisa do passado para nós". Mais recentemente, em 1984, o professor de filosofia Arthur C. Danto anunciou o "fim da arte".

Mas não queria dizer com isso que os artistas tivessem deixado de produzir; antes, estava se referindo ao fim da história da arte. Durante boa parte dessa história, os artistas - dos escultores helenistas aos pintores acadêmicos realistas franceses do séculoXIX — seempenharam na representação realista do mundo. Porém, com o advento do modernismo, o realismo passou o bastão adiante, dirigindo-se rapidamente a seu desfecho - as pinceladas se tornaram visíveis e enfáticas, a cor passou a denotar mais expressão do que autenticidade, e as figuras tornaram-se cada vez mais esboçadas e cruas até não restar nada além da pura abstração. Nos anos 1980, contudo, essa progressão linear foi abruptamente interrompida à medida que o mundo da arte ingressou em uma nova era, pluralista. Esta se definia não pela predominância de determinada escola ou movimento, mas exatamente pela ausência de qualquer coisa desse tipo. 
No mesmo ano em que declarou o fim da história da arte, Danto começou a escrever crítica de arte na revista The Nation. Sem ter nenhum movimento hegemônico para defender, nem teorias sobre o futuro da arte para profetizar, ele redefiniu a atividade do crítico de arte ao declarar-se "o primeiro crítico de arte pós-histórico".

De certa maneira, a mudança de rumo na carreira de Danto em direção à crítica de arte não surpreende. Após estudar arte na Universidade Estadual de Wayne, mudou-se para Nova York nos anos 1950, onde teve uma curta carreira artística. "Eu fiz algumas exposições", lembra-se, "e pintava como Franz Kline, só que figurativamente”. Mas, além de batalhar por uma carreira artística, Danto também estudava filosofia. "Gostava mais de escrever, então simplesmente parei. Dedicar-se à filosofia e à arte simultaneamenteera como viver duas vidas paralelas — e uma vida já é suficiente." A partir desse momento, Danto tornou-se "exclusivamente filósofo", como escreveu em seu livroAfter the end of art [Depois do fim da arte], vindo a assumir a função de professor na Universidade de Colúmbia em 1966.

Nos anos 1960, Danto foi "atropelado pela pop art", um movimento que incorporava o visual impetuoso da cultura de consumo. Em Nova York, um encontro com as Brillo box, de Andy Warhol, em 1964, na galeria Stable, lhe forneceu a inspiração para escrever sobre o novo movimento - mas tendo em vista outros filósofos. "Eu pensei: se isso é possível [uma caixa de sabão em pó ser vista como arte], qualquer coisa é possível. Então me ocorreu que era possível escrever filosoficamente sobre a questão", lembra. Danto estava intrigado com a relação problemática entre as duas caixas de Brillo - a "verdadeira" e aquela presente na instalação de Warhol. Uma vez que são idênticas, pensou Danto, o que faz de uma delas uma obra de arte? Essa questão o levou a escrever The transfiguration of commonplace [A transfiguração do lugar-comum], seu primeiro livro sobre arte.

Desde então, Danto publicou diversos livros sobre o assunto, assim como cinco coletâneas de artigos seus escritos para a The Nation. Em 2003, seu livro The Madonna of the future [A Madona do futuro] ganhou o Prix Philosophie, e seu livro mais recente, publicado este ano - Unnatural wonders:essays from the gap between art and life [Maravilhas não-naturais: ensaios sobre a distância entre arte e vida] —, foi amplamente elogiado. Atualmente faz a curadoria da exposição "A arte de 11/9", uma exposição na galeria Apex Art em Nova York, aberta em sete de setembro de 2005.

Danto mora a alguns quarteirões da Universidade de Colúmbia, num apartamento que mais parece uma casa. É um lugar admirável — arejado, colorido eeclético - com obras de arteespalhadas por todos os lados (algo normal, no final das contas, na casa de um crítico de arte e de uma artista). Mais surpreendente, talvez, seja a diversidade da coleção: há um quadro trompe l'oeil no estilo do realista do século XIX William Harnett, pinturas abstratas de Sean Scully e as exuberantes peças de sua mulher, Barbara Westman. A diversidade sugere que Danto pratica aquilo que prega: o crí- 
tico celebra as virtudes do pluralismo, a idéia de que não há mais uma maneira única de fazer arte. Abstração, realismo, minimalismo e expressionismo têm todos as mesmas pretensões; cada um é um meio entre outros.

Oquepoderia pareceruma progressãolinearéantes algo como uma fita de Moebius: a progressão da arte começa em Lascaux para terminar, quase quinze mil anos depois, com artistas que desejam pintar como homens das cavernas.Agora, depois do fim da arte, vale tudo.(Natasha Degen)

Natasha Degen - Vocêé professor de filosofia em Colúmbia há quase quarenta anos. Como surgiu seu interesse pela arte?

Não estava nos meus planos ser crítico de arte. Encontrei o que parecia ser minha vocação na filosofia analítica e tinha (e ainda tenho) grandes ambições filosóficas. Meus escritos se dirigiam principalmente a um público de filósofos profissionais, e meu maior objetivo era elaborar um sistema filosófico baseado no conceito de representação, em suas diferentes acepções. Eu comecei, é verdade, como artista, e vim para Nova York tendo em vista uma carreira artística. Fui atraído pelo expressionismo abstrato nos anos 1950, mas abandonei o projeto quando me dei conta de que meus interesses me inclinavam muito mais à filosofia.

Eu não tinha interesse filosófico pela arte até o advento da pop art, que me indicou as possibilidades da reflexão filosófica sobre a arte em geral. Em 1964 apresentei um artigo à Associação Filosófica Americana, baseado na obra de Andy Warhol, Robert Rauschenberg e de alguns artistas do minimalismo. Chamava-se "O mundo da arte", e nele eu tentava redirecionar a forma em que a filosofia da arte era praticada. Não cheguei, no entanto, a desenvolver as idéias, já que estava ocupado com meu sistema, a respeito do qual publiquei diversos livros. Mas, no fim dos anos 1970, comecei a escrever um livro intitulado $A$ transfiguração do lugar-comum, que aplicava os princípios do sistema à filosofia da arte. Esse livro era dirigido não só aos filósofos, mas também ao meio das artes, do qual as questões tinham brotado.

\section{Como começou sua relação com a The Nation?}

Em 1984, Betsy Pochoda, depois de passar um curto período na Vanity Fair, voltou à The Nation para ser a editora de literatura. A revista, à época, não tinha um crítico de arte ativo, já que Lawrence Alloway, que desempenhava a função, estava gravemente doente. Betsy procurava alguém para substituí-lo, e meu nome lhe foi sugerido por Bem Sonnemberg [ex-editor de Grand Street], que havia gostado muito de $A$ transfiguração do lugar-comum. Ele disse que eu aparentava saber muito sobre arte contemporânea. Na verdade, eu sabia muito "para um filósofo", e meus conhecimentos eram razoavelmente restritos à produção dos anos 1960. Um belo dia, recebo um telefonema de Betsy, a quem não conhecia, me convidando para escrever, sobre arte, para a revista. Nunca tinha pensado em fazer isso, mas as perspectivas me animaram muito. Propus escrever sobre uma mostra chamada "Blam! 
- Arte de Nova York 1957-1964", no Whitney Museum. Tratava-se, afinal de contas, da produção artística que me havia interessado filosoficamente, e o artigo foi bem recebido. Recebi cem dólares pelo trabalho, e tive a satisfação de vê-lo impresso quase imediatamente, duas coisas que nunca haviam acontecido com qualquer coisa que eu já tivesse publicado. Adorei a experiência, e logo me tornei crítico da revista, função que desempenho até hoje.

Como foi a transição da academia para a crítica de arte dirigida a um público mais amplo?

Comecei a fazer crítica de arte fazendo crítica de arte. Foi algo fácil e natural, mas nunca teria me candidatado de forma espontânea para a função. Teriam me considerado mais qualificado do que o necessário e excessivamente acadêmico. Ninguém fora do círculo filosófico conhecia meu trabalho. Mas descobri que, como crítico de arte, poderia fazer algo que não podia fazer como filósofo: filosofar. O telefonema de Betsy mudou minha vida. Foi uma descoberta casual, como a de Lana Turner numa lanchonete. Tentei incorporar à minha atividade como crítico lições que aprendi com a filosofia: escrever com clareza, concisão e coerência. Muito da crítica de arte não passava (e ainda não passa) de um amontoado de jargões e idéias vagas. Divertia-me escrevendo os artigos e queria que o leitor se divertisse ao lê-los. E, porque sou professor, queria que os leitores aprendessem novas formas de pensar sobre arte.

\section{Que importância tem a crítica de arte para a The Nation?}

A crítica de arte profissional, por oposição ao ensaísmo beletrista sobre arte, começou para valer na The Nation nos anos 1860. Peter Meyer e eu organizamos uma antologia com as críticas da revista, que começa com uma carta de P. T. Barnum ao editor. Demos à antologia o nome Brushes with history, pois é possível acompanhar a arte americana através da reação da revista às exposições e controvérsias. Os criadores da revista eram discípulos de John Ruskin, que acreditava que se a arte for sólida, então a sociedade o será. Para reformar a sociedade, bastaria reformar a arte. Hoje em dia, claro, ninguém acredita nisso, mas não há como negar que os artistas, sobretudo os contemporâneos, abordam os dilemas mais urgentes enfrentados pela sociedade contemporânea, de maneira que encarar a produção artística nos leva necessariamente a pensar sobre os problemas que nos desafiam enquanto sociedade.

O mundo das artes é altamente globalizado. Cada vez mais os mesmos valores artísticos são globalmente compartilhados, o que significa que no fim das contas outros valores também o serão. Desse ponto de vista, as coisas mudaram muito desde que comecei a escrever sobre arte. Há pouco tempo, recebi uma carta de Khalad al-Hamzah, um artista da Jordânia que obteve financiamento para realizar um trabalho conceitual sobre algumas de minhas idéias. Fiquei surpreso ao saber que em um 
país como esse, do qual recebemos quase exclusivamente notícias políticas, a vanguarda artística trabalha com conceitos que podem ser adotados pela vanguarda em todo equalquer lugar. O Islã proíbe imagens, mas está aberto para a arte conceitual - e hoje grande parte da arteé conceitual. Parece haver um terreno fértil para os filósofos!

Jáque esta entrevista épara a The Nation, devofazer pelo menos uma pergunta sobre politica. Em um artigo publicado ano passado na Artforum, você afirmou que "nos Estados Unidos, a separação arte e Estado é quase tão forte quanto entre Igreja e Estado". Que papel os governos, e o nosso governo especificamente, desempenham no apoio à arte?

ANational Gallery de Washingtoné talvez o único museu nacional que não é também um monumento ao espírito nacional. Não há ali nenhuma aura patriótica. Isso é típico do sistema governamental norte-americano: nossa arteévista antes como uma questão de interesse individual do que nacional. É uma benção, acredito eu, que o governo não se importe com o que acontece na arte. É, acima de tudo, uma questão de liberdade individual. Essa postura tem respaldo em um dos direitos fundamentais: direito à liberdade e à busca por felicidade. Até Rudolph Giuliani [ex-prefeito de Nova York] reconhecia isso, indagando tão-somente se é correto usar impostos para financiar obras de arte que são contrárias aos nossos valores.

Eu aceito o fato de que meus impostos acabem financiando um governo cujas decisões são recorrentemente contrárias aos meus valores, e é dessa forma que as coisas funcionam em uma sociedade aberta e livre, baseada num sistema representativo. A Primeira Emenda protege a liberdade de expressão, mas há boas razões para reafirmarque a liberdadeéuma questão de interesse nacional, já que um debate livree abertoéessencial para chegarmos a decisões coletivas. O museu é um fórum, e grande parte da arte tem conotações políticas. Mas há ainda um longo caminho, que se relaciona à educação, para que finalmente consigamos convencer os cidadãos a aceitarem de bom grado que seu dinheiro seja aplicado no patrocínio a um tipo de arte que eles muitas vezes acham repugnante. A educação pode diminuir essa rejeição, mas não a eliminar. Não há nenhuma regra a priori que determine que qualquer tipo de arte será apreciado por todas as pessoas.

Gostaria também de falar sobre suas idéias a respeito de filosofia da arte. Duchamp colocou objetos cotidianos numa exposição e os considerou como objets-trouvés. As pinturas de telefones de Moholy-Nagy foram feitas em uma fábrica; as mãos do artista não encostaram na tela. De Donald Judd a Jeff Koons, artistas deixaram a realização de suas obras a cargo de engenheiros e artesãos. Uma vez aceito que artistas podem fazer obras de arte sem na realidade fazer coisa alguma, a habilidade e técnica artísticas ainda têm relevância?

Por ser dadaísta, Duchamp se opunha à concepção do Grande Artista como um herói cultural.Ele sentia que a adoração exagerada do artista levaria a conseqüências políticas desastrosas. Então adotou uma postura 
antiartística. Tinha desprezo pelo olhar, pelo toque, pela mão do artista. Criação sem intervenção direta era um ideal dadaísta — daí os ready-mades. A conseqüência foi a noção de "trabalho manual" deixar de fazer parte do conceito de arte - a versão da beleza que resultou do projeto dadaísta de a destruir. Isso abriu a possibilidade de o artista transferir a tarefa de realização da obra a outros, como no caso de Koons ou, por razões diferentes, de Donald Judd. A arte estava na idéia, independente de quem a executasse. No caso de Judd, há uma certa estética industrial que se tornou artisticamente apreciável. Ele sabia que não poderia fazer beiradas e cantos com a mesma precisão que as máquinas. Mas éclaro que ainda existe arte ali onde também podemos admiraro gesto — como na obra de Guston ou De Kooning. Nesses casos, a mão do artista compõe o sentido do trabalho. O interessante do pluralismo é que não existe uma maneira única de fazer as coisas. Por isso, sou partidário antes de uma estética do sentido do que de uma estética da forma. Meu interesseestá em encontrar esses sentidos e procurar explicar como eles estão incorporados nas obras de arte. É principalmente disso que tratam os meus escritos.

\section{Por último: que artistas e obras você mais admira?}

Tenho um gosto um pouco conservador. Adoro a arte francesa do século XVIII, Watteau e Chardin principalmente. Gosto muito de Morandi e Modigliani. Dentre os artistas contemporâneos, gosto muito dos que fazem pintura abstrata - Robert Mangold, Sean Scully, David Reed. Mas nem toda arte importante é necessariamente fácil de gostar. Não posso dizer que eu goste do trabalho de Jeff Koons - mas o considero importante. Quem consegue verdadeiramente gostar do trabalho de Duchamp? Só não gosto de ser manipulado. Por causa disso, detesto Francis Bacon. Mas perdôo Norman Rockwell, já que sou dado a sentimentalismos. Eu sinceramente gostaria que o mundo fosse muito mais parecido com o mundo dele do que de fato é. Gosto de Robert Rauschenberg por ter apagado um desenho de De Kooning, gosto dessa petulância. Poderia ficar horas e horas falando sobre isso! 